\title{
Factors Influencing Choice of Inguinal Hernia Repair Technique
}

Dixon Osilli, Mark Awori, Daniel Ojuka

School of Medicine, University of Nairobi

Correspondence to: Dr. Osilli Dixon, P.O. Box 19762 - 00202, Nairobi, Kenya. Email: dxosilli@gmail.com

\begin{abstract}
Background: Inguinal hernia repair surgery is one of the most frequently performed surgical procedures worldwide. This study sought to highlight factors that may influence decisions concerning inguinal hernia repair techniques. Methods: This descriptive crosssectional study was carried out in September 2014 among surgical trainees and surgeons. Data collected included: qualification of the operating doctor, level at which practical training on inguinal hernia repair occurred, awareness of the various inguinal hernia repair methods, inguinal hernia repair method(s) used for the past three (most recent) inguinal hernia operations and reasons for using that /those repair method(s). Results: Fifteen surgeons and sixty surgical trainees were recruited. Awareness levels and practical training were highest in the modified Bassini and Lichtenstein repair techniques. Experienced peers play a major role in training on
\end{abstract}

\section{Introduction}

Inguinal hernia is a common pathology encountered by general surgeons, comprising $75 \%$ of all abdominal wall hernias $(1,2)$. Inguinal hernia repair is the second most common general surgical operation worldwide (after appendectomy) accounting for 10 to $15 \%$ of all surgical procedures (3).

Laparoscopic and Lichtenstein mesh repair are becoming popular in recent days as they are associated with rapid return to normal activities with low recurrence rates $(4,5)$. These repair methods have come to replace the traditional suture repairs of Bassini and McVay in many developed nations.

Lichtenstein repair has long been considered the 'gold standard' in inguinal hernia surgery (6). The National the various repair techniques. The modified Bassini technique is preferred in emergency inguinal hernia repair; conversely, open mesh repair (Lichtenstein and PHS/plug) is preferred in elective cases. Reasons influencing choice of repair technique include training on the technique among others. Conclusion: Multiple factors affect the choice of inguinal hernia repair technique some of which are based on evidence while others are attributed to availability of resources and training (or lack thereof).

Key words: Inguinal Hernia, Surgical Technique, Choice of Technique

Ann Afr Surg. 2017;14(1): 3-9.

DOI: https://dx.doi.org/10.4314/aas.v14i1.2

(C) 2017 Annals of African Surgery. This work is licensed under the Creative Commons Attribution 4.0 International License.

Institute of Clinical Excellence (NICE) from the United Kingdom and the National Agency for Accreditation and Evaluation in Health (ANAES) from France recommended it for inguinal hernia repair $(1,2)$. It is easy to learn and perform. The Lichtenstein Hernia Institute and the British Hernia Centre reported very low recurrence rates in thousands of cases (7). It is also suitable for outpatient surgery using local anesthesia (5).

Laparoscopic repairs provide very good results where surgeons have the expertise (8). They result in very low postoperative pain, fewer wound infections, and quick return to daily activity. The totally extra-peritoneal (TEP) and trans abdominal pre-peritoneal (TAPP) approaches have comparable long-term outcomes in 
terms of incidence of chronic groin pain, quality of life and resumption of normal activities (9). A comparison of the TEP and Lichtenstein techniques in the LEVEL trial did not find any differences in recurrence rates and chronic pain (10).

Traditional suturing techniques such as Shouldice, Darning, Desarda and Modified Bassini are still practiced widely in developing countries (11). The management of inguinal hernia poses therapeutic challenges to general surgeons practicing in resourcelimited countries. Late presentation of the disease coupled with lack of modern therapeutic facilities such as laparoscopy and meshes are among the hallmarks of the disease and its management in developing countries (12). In these countries, approximately 65\% of inguinal hernias are repaired as emergencies, with a bowel resection rate of $24 \%$ (13). Early presentation and elective repair of inguinal hernia have been reported to eliminate the morbidity and mortality associated with this very common problem.

In a 5-year retrospective study of adult inguinal hernia patients at $\mathrm{KNH}, 17.9 \%$ of patients had emergency surgery; while the repair method employed for all the hernias was the Bassini repair (14).

Hands-on instruction is an integral component of surgical education in the West (15). Graduate surgical education in the United States, for example, follows a model of graded clinical responsibility and operative experience, with continuous evaluation, throughout a residency program. The program requirements for Residencies in Surgery, as defined by the Accreditation Council for Graduate Medical Education, state:

"Operative skill is essential and can be acquired only through personal experience and training. The program must provide for sufficient operative experience to train qualified surgeons, taking into account individual capability and rate of progress" (16).

There are a number of studies that compare outcomes of procedures done at teaching hospitals by residents and those procedures performed by attending surgeons (17). Almost uniformly, these studies show no negative effect on outcome when patients are operated on at hospitals with residents involved in patient care. It has been reported that, when surgical procedures were performed with low levels of attending surgeon supervision, complication levels and mortality were raised (18).

There is paucity of published data on the choice of surgical management of inguinal hernias in our environment. The frequencies of the various surgical repair techniques and the bases for different technique preferences remain largely unknown. Data on hernia surgery training is also lacking.

This study aimed therefore, to tackle these two questions: For surgeons and surgical trainees involved in inguinal hernia repair at $\mathrm{KNH}$, what are their recent operative techniques? And what factors influence the choice of inguinal hernia repair technique?

\section{Methods}

This was a descriptive cross-sectional study involving a one-time interaction with the subjects carried out in September 2014 at the Kenyatta National Hospital (KNH) General Surgical Unit. The study targeted the entire population of surgeons and surgical trainees at the General Surgical Unit of KNH.

By census (19), the total number of surgeons and surgical trainees who do inguinal hernia surgery at KNH (at the time of the study) formed the study population $(\mathrm{N}=75)$.

Self-administered questionnaires were used for data collection. One author (OD) assisted by a trained research assistant (a medical intern) administered consent and distributed (and collected) the questionnaires. Data collected included: qualification of the operating doctor, level at which practical training on inguinal hernia repair occurred, awareness of the various inguinal hernia repair methods, inguinal hernia repair method(s) used for the past three (most recent) inguinal hernia operations and reasons for using that /those repair method(s). It was assumed that each surgical trainee/ surgeon did his/her case without the help of a fellow surgical trainee/ surgeon respectively.

The collected data was entered into a passwordprotected customized MS Access database with inbuilt checks to minimize on data entry error. These data entry were compared with the hard copy forms to check for errors, inconsistencies, missing and duplicate entries

Descriptive statistics were used to analyze the various attributes of the data. Differences in the various attributes were calculated by the $\chi 2$ test for categorical variables using Stata software.

Data is presented in the form of graphs and tables.

\section{Results}

\section{Awareness of Hernia Repair Techniques}

All of the 75 questionnaireswere completed.Awareness Level and Practical Training on Various Hernia Repair Techniques Awareness level and practical training was highest in the modified Bassini and Lichtenstein hernia repair techniques among both surgeons and surgical trainees. None of the respondents was trained in the McVay repair technique.

The results are summarized in table 1 : 
Table 1: Comparison of hernia repair techniques' awareness and training

\begin{tabular}{|l|l|l|l|l|}
\hline \multirow{2}{*}{$\begin{array}{l}\text { Hernia repair } \\
\text { technique }\end{array}$} & \multicolumn{2}{|l|}{ Awareness of the technique } & \multicolumn{2}{l|}{ Practical training on the technique } \\
\cline { 2 - 5 } & $\begin{array}{l}\text { Consultants } \\
\text { (Percent) }\end{array}$ & $\begin{array}{l}\text { Surgical trainees } \\
\text { (Percent) }\end{array}$ & $\begin{array}{l}\text { Consultants } \\
\text { (Percent) }\end{array}$ & $\begin{array}{l}\text { Surgical trainees } \\
\text { (Percent) }\end{array}$ \\
\hline Modified Bassini & 100 & 100 & 100 & 98 \\
\hline Marcy & 26 & 5 & 0 & 0 \\
\hline Shouldice & 87 & 93 & 47 & 23 \\
\hline McVay & 60 & 37 & 0 & 0 \\
\hline Maloney Darn & 27 & 7 & 13 & 0 \\
\hline Desarda & 33 & 20 & 0 & 2 \\
\hline Lichteinstein & 100 & 100 & 100 & 88 \\
\hline PHS/plug & 87 & 88 & 93 & 78 \\
\hline TIPP & 60 & 35 & 33 & 2 \\
\hline GPRVS & 73 & 12 & 40 & 2 \\
\hline TAPP & 87 & 58 & 67 & 12 \\
\hline TEP & 87 & 48 & 53 & 7 \\
\hline
\end{tabular}

\section{Level at Which Practical Training on Inguinal} Hernia Repair Occurred

The modified Bassini technique was taught to most surgical trainees by an experienced peer outside of residency (58\%) while 33\% of the surgeons learnt the technique as undergraduates. None of the respondents received training in the modified Bassini technique during workshops/ conferences (Figure 1).

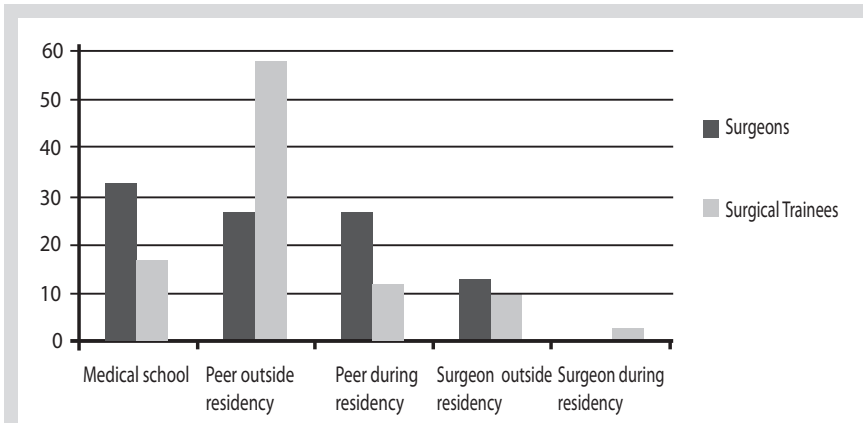

Figure 1: Level at which practical training occurred - Modified Bassini

On the other hand, the Lichtenstein method was taught to most surgical trainees by an experienced peer during residency; while an equal number of surgeons learned the Lichtenstein method through workshops/ conferences and through an experienced peer during residency. None of the respondents received training in the Lichtenstein repair technique in undergraduate medical school (Figure 2).

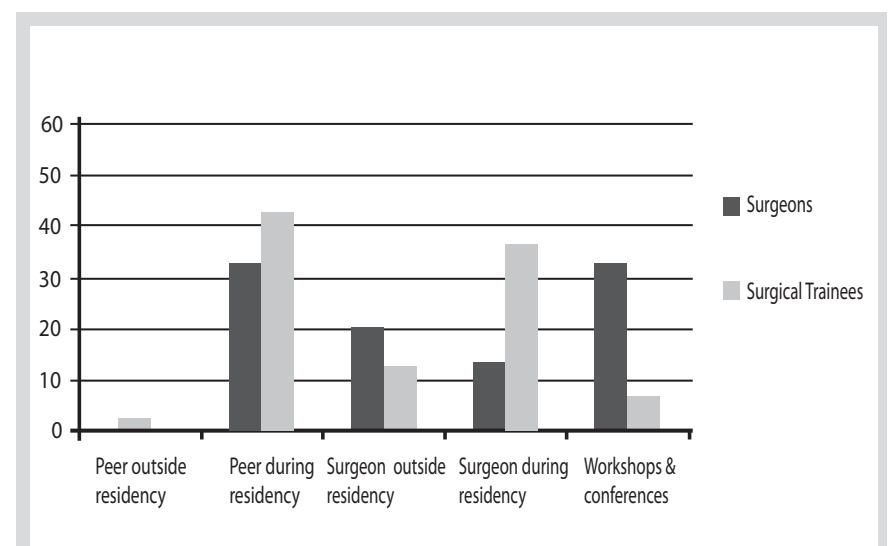

Figure 2: Level at which practical training occurred - Lichteinstein

Most surgical trainees (45\%) were taught the PHS/plug method by a surgeon during residency. Workshops and conferences played a big role in the skills acquisition by the surgeons for the laparoscopic hernia repair methods $(90 \%$ and $88 \%$ for TAPP and TEP methods respectively).

Hernia Repair Methods Used for the Last Three Inguinal Hernia Operations

The 3 most commonly used repair methods were the Lichtenstein, PHS/plug and modified Bassini. The modified Bassini was the commonest method used in emergency cases $(71 \%)$ while the Lichtenstein method was preferred by most for the elective repairs (44\%) (Table 2). 
Table 2: Hernia Repair Methods Used

\begin{tabular}{|c|c|c|c|c|c|c|}
\hline \multirow{3}{*}{$\begin{array}{l}\text { Hernia repair } \\
\text { method }\end{array}$} & \multicolumn{4}{|c|}{ Surgery Type } & \multirow{2}{*}{\multicolumn{2}{|c|}{ Total }} \\
\hline & \multicolumn{2}{|c|}{ Elective cases } & \multicolumn{2}{|c|}{ Emergency cases } & & \\
\hline & Frequency & $\%$ & Frequency & $\%$ & Frequency & $\%$ \\
\hline Modified Bassini & 15 & 9 & 37 & 71 & 52 & 23 \\
\hline Shouldice & 0 & 0 & 3 & 6 & 3 & 1 \\
\hline Lichtenstein & 77 & 44 & 9 & 17 & 86 & 38 \\
\hline PHS/plug & 75 & 43 & 3 & 6 & 78 & 35 \\
\hline TIPP & 1 & 1 & 0 & 0 & 1 & 0.5 \\
\hline TAPP & 4 & 2 & 0 & 0 & 4 & 2 \\
\hline TEP & 1 & 1 & 0 & 0 & 1 & 0.5 \\
\hline Total & 173 & 100 & 52 & 100 & 225 & 100 \\
\hline
\end{tabular}

For these 3 most common methods there was a statistically significant difference between their use and the type of hernia surgery - whether elective or emergency ( $p$-value $=<0.0001)$. The modified Bassini is preferred in emergency as opposed to elective surgery ( $p$-value <0.0001). Conversely, the open mesh repairs (Lichtenstein and PHS/plug) are preferred in elective, as opposed to emergency, surgery ( $p$-value $=<0.0001$ ).
None of the respondents used the Maloney Darn, Desarda and GPRVS repair methods despite some of them having practical training on these methods.

\section{Reasons for Picking on the Hernia Repair Methods Used}

Various reasons were cited by the respondents as a basis for their choices in the different hernia repair techniques. The most common reasons for 4 of the repair techniques are depicted in table 3 :

Table 3: Reasons for Picking on the Various Repair Techniques

\begin{tabular}{|l|l|l|l|l|l|l|}
\hline & $\begin{array}{l}\text { Training on } \\
\text { Technique }\end{array}$ & $\begin{array}{l}\text { Ease of } \\
\text { Technique }\end{array}$ & $\begin{array}{l}\text { Availability } \\
\text { of Repair } \\
\text { Material }\end{array}$ & $\begin{array}{l}\text { Early } \\
\text { Return to } \\
\text { Work }\end{array}$ & $\begin{array}{l}\text { Decreased } \\
\text { Recurrent } \\
\text { Rate }\end{array}$ & $\begin{array}{l}\text { Perceived } \\
\text { Reduced } \\
\text { Risk of } \\
\text { Complications }\end{array}$ \\
\hline $\begin{array}{l}\text { Modified } \\
\text { Bassini }\end{array}$ & $44 \%$ & $49 \%$ & $19 \%$ & $10 \%$ & $2 \%$ & $33 \%$ \\
\hline Lichtenstein & $77 \%$ & $60 \%$ & $72 \%$ & $27 \%$ & $62 \%$ & $12 \%$ \\
\hline PHS & $77 \%$ & $36 \%$ & $82 \%$ & $27 \%$ & $62 \%$ & $24 \%$ \\
\hline TAPP & $75 \%$ & $25 \%$ & $75 \%$ & $100 \%$ & $50 \%$ & $75 \%$ \\
\hline
\end{tabular}

\section{Discussion}

\section{Knowledge in Hernia Repair Techniques}

All the respondents in the study had a theoretical understanding of the Bassini and Lichtenstein repair methods. The Bassini method of hernia repair was described in the late 19th Century. The principles behind this repair method [and its modifications] remain relevant even in the present day. It is no surprise then that all the respondents were familiar with it. The Lichtenstein repair, on the other hand, is the most common mesh repair worldwide (10).

It is important to note that though the Shouldice method has been described as being complex, theoretical understanding among the respondents was quite high. The PHS/plug method of repair was also understood by a sizeable number of the respondents. The less common suture repair methods such as McVay, Maloney darn and Desarda were not widely 
known by the respondents. However, this should not imply that knowledge (and training) on multiple repair techniques is superior to having a thorough understanding on fewer repair options. A case in point is the Shouldice Hernia Centre in Canada that solely utilizes the Shouldice repair technique with very good outcomes (2).

No other study has looked at awareness of the various hernia repair techniques.

\section{Hernia Repair Technique Training}

The majority of the respondents were trained in the modified Bassini technique. The majority of the surgical trainees acquired this skill prior to surgical residency as medical officers. The technique is used extensively in many peripheral hospitals due to resource limitation in the adaptation of the mesh repair techniques. It is hence the method of hernia repair that the surgical trainees are more likely to learn prior to residency. Very little practical training in surgery occurs in medical school as undergraduates. Only 20\% of the respondents learned the modified Bassini technique as undergraduates. None of them learned any other technique at that level of their training.

A higher proportion of surgeons were conversant with the laparoscopic methods of repair compared to the trainees. This trend does show that knowledge and skills transfer in laparoscopic hernia repair may not be adequate. This may be due to the fact that resources and infrastructure needed to adequately train in this form of surgery are not that readily available in KNH as is the case in many public facilities in developing countries. This argument is supported by the fact that most of the surgeons honed their skills in laparoscopic hernia surgery during workshops and conferences [90\% and 88\% for TAPP and TEP methods respectively] and not in medical school [as undergraduate students or as residents]. It is also possible that most of the surgeons were surgical trainees at a time when laparoscopic hernia repair was not used widely - hence they were not exposed to it during their time in school. These avenues of learning [workshops and conferences] are yet to be fully exploited by the surgical trainees. It is important though to note that the learning curve for laparoscopic TEP repair is about $60-80$ cases (20); hence workshops and conferences are by no means adequate avenues for proficiency and skill acquisition. An interesting observation is that while theoretical understanding of the Shouldice method is quite high, only $28 \%$ of the respondents can practically perform it. This does underline the complexity of this suture repair method that has exceptionally good outcomes in the hands of the experienced surgeon (21).

The Lichtenstein method is the repair method majority learn while in residency. Experienced peers at this level of training (residency) do play an important role in passing on skills to the less experienced surgical trainees - as is evidenced by training in the Lichtenstein repair method.

Lichtenstein, PHS/plug and modified Bassini are the three most common repair methods used in $\mathrm{KNH}$. The modified Bassini technique is the procedure of choice in most emergency hernia surgeries. This may be informed by the fact that use of mesh material in the presence of contamination has traditionally been contraindicated (22). This practice, however, is now being challenged (23).

Of the 225 operations sampled, $77 \%$ were elective cases. This is not in keeping with the literature that states that majority of the hernia operations done in most African institutions are emergencies (13). This may be because the study was done at a Level 6 facility. Facilities downstream may give a different picture altogether.

\section{Reasons for Picking on the Repair Methods}

Various reasons were given for picking on one repair method over the other. In the modified Bassini method, respondents cited ease of technique, training on the technique and perceived reduced risk of complications as the most common reasons for picking it. This is in keeping with the emergency nature of the cases bearing in mind the increased risk of surgical site infection with use of prostheses (22).

As for the open mesh repair methods [Lichtenstein and PHS/plug] the three most commonly cited reasons for their use were: training on the technique, availability of repair material and equipment, and decreased recurrence rate. These were the two methods commonly used in elective hernia surgery. Studies have consistently shown the supremacy of these repair techniques to the suture-based ones particularly in terms of hernia recurrence (5). That $87 \%$ of all the elective cases were repaired using an open mesh method is testament to the fact that meshes are readily available at $\mathrm{KNH}$.

Of the laparoscopic mesh repair methods, TAPP was preferred to TEP [though they were only employed in 5 of the 225 operations]. Patient early return to work, training on the technique, availability of repair material and equipment, and perceived reduced risk 
of complications were some of the reasons cited for using the laparoscopic repair methods. Not many among the respondents were trained in laparoscopic hernia repair compared to open repair. Laparoscopy equipment may also not be readily available at $\mathrm{KNH}$. Interestingly, the evidence available does not support superiority of laparoscopic mesh hernia repair in terms of early return to work and low complication rate - even though less post-operative pain has been demonstrated with the use of laparoscopy as opposed to open mesh repair (10).

A study done in Poland (24) showed that all respondents were familiar with and able to perform tension-free techniques (24). Forty-four percent were influenced by their individual professional skills in selecting the technique. Another $44 \%$ based their decision on trends in their hospital, and only $22 \%$ considered the patient's preferences. None of the respondents in our study cited trends in their hospital or patient preference as a factor influencing what repair technique they used.

\section{Conclusion}

Multiple factors affect the choice of inguinal hernia repair technique among the surgeons and surgical trainees at KNH. Some of the factors cited are based on evidence while others have to do with availability of resources and training (or lack thereof).

Contrary to the prevailing opinion that meshes are not readily available in public institutions in developing countries, open mesh repairs, particularly for elective cases, are commonly used in $\mathrm{KNH}$.

Workshops and seminars (some offered by professional associations) are an avenue of knowledge transfer particularly in low-resource settings. Their value in skills acquisition though is open to question; and can only be determined upon assessment of clinical outcomes.

\section{References}

1. Simons MP, Aufenacker T, Bay-Nielsen M, et al. European Hernia Society Guidelines on the Treatment of Inguinal Hernia in Adult Patients. Hernia. 2009; 13:343-403.

2. Read RC. Herniology: Past, Present and Future. Hernia. 2009; 13: 577-80.

3. Hachisuka T. Femoral Hernia Repair. Surg Clin of N Am. 2003; 83:1189-1205.

4. Eklund AS, Montgomery AK, Rasmussen IC, et al. Low Recurrence Rate after Laparoscopic and Open Inguinal Hernia Repair. Ann Surg. 2009; 249:33-8.
5. McGillicuddy JE. Prospective Randomized Comparison of the Shouldice and Lichtenstein Hernia Repair Procedures. Arch Surg. 1998; 133:974.

6. Anadol AZ, Akin M, Kurukahvecioglu O, et al. A Prospective Comparative Study of the Efficacy of Conventional Lichtenstein versus Self-adhesive Mesh for Inguinal Hernia. Surg Today. 2011; 41(11):1498-503.

7. Butter M, Redecke J, Köninger J. Long-term Results of a Randomized Clinical Trial of Shouldice, Lichtenstein and Transabdominal Preperitoneal Hernia Repairs. Br J Surg. 2007; 94(5):562 - 65.

8. Zendejas B, Cook DA, Bingener J, et al. Simulationbased Mastery Learning Improves Patient Outcomes in Laparoscopic Inguinal Hernia Repair: A Randomized Controlled Trial. Ann Surg. 2011; 254 (3): 502-9

9. Bansal VK, Misra MC, Babu D, et al. A Prospective Randomized Comparison of Long-term Outcomes: Chronic Groin Pain and Quality of Life Following Totally Extraperitoneal (TEP) and Transabdominal Pre-peritoneal (TAPP) Laparoscopic Inguinal Hernia Repair. Surg. Endosc. 2013; 27 (7): 2373-82

10. Langeveld HR, van Riet M, Wiedema WF, et al. Total Extraperitoneal Inguinal Hernia Repair Compared with Lichtenstein (the LEVEL-trial): A Randomized Controlled Trial. Ann. Surg. 2010; 251 (5): 819-24

11. Fall B, Betel ME, Diarra O, et al. Complications of Treatment of Adult's Groin Hernia: A Report of 100 Cases Comparative Study Between Bassini and Mac Vay's Techniques. Dakar Med. 2005; 50:37-40.

12. Mbah N. Morbidity and Mortality Associated with Inguinal Hernia in Northwestern Nigeria. West Afr J Med. 2007; 26:288-92.

13. Ohene-Yeboah, M. Strangulated External Hernias in Kumasi. W Afr J Med. 2003; 22(4): 310-13 .

14. Mkuzi E. Inguinal Hernia and Hernia Repair in Adults: The Disease as Seen at Kenyatta National Hospital Over a Five Year Period (Dissertation). Nairobi: University of Nairobi; 1984.

15. Rutkow IM. Demographic and Socioeconomic Aspects of Hernia Repair in the United States in 2003. Surg Clin N Am. 2003; 83: 1045-51.

16. American Medical Association (COR). Graduate Medical Education Directory, 2012-2013. Amer. Medical Assn. 2012.

17. Wilkiemeyer M, Pappas TN, Giobbie-Hurder A, et al. Does Resident Postgraduate Year Influence the Outcomes of Inguinal Hernia Repair? Ann Surg. 2005; 241(6):879-884. 
18. Fallon WF Jr, Wears RL, Tepas JJ III. Resident Supervision in the Operating Room: Does this Impact on Outcome? Trauma 1993; 35:556-560.

19. Dattalo P. Determining Sample Size: Balancing Power, Precision, and Practicality. Oxford University Press; 2008

20. Choi YY, Kim Z, Hur KY. Learning Curve for Laparoscopic Totally Extraperitoneal Repair of Inguinal Hernia. Can J Surg. 2012; 55(1):33-6.

21. Amato B, Moja L, Panico S, et al. Shouldice Technique versus other Open Techniques for
Inguinal Hernia Repair. Cochrane Database Syst Rev. 2009; 4:CD001543.

22. Gilbert AI, Felton L. Infection in Inguinal Hernia Repair: Considering Biomaterilas and Antibiotics. Surg Gynecol Obstet. 1993; 177:126-30.

23. Atila K, Guler S, Inal A, et al. Prosthetic Repair of Acutely Incarcerated Groin Hernias: A Prospective Clinical Observational Cohort Study. Langenbecks Arch Surg. 2010; 395:563.

24. Smietański M, Lukasiewicz J, Bigda J. et al. Factors Influencing Surgeons' Choice of Method for Hernia Repair Technique. Hernia. 2005; 9(1):42-5. 